\title{
Effect of white matter disease on functional connections in the aging brain
}

\author{
A F Leuchter, J J Dunkin, R B Lufkin, Y Anzai, I A Cook, T F Newton
}

\begin{abstract}
Periventricular white matter hyperintensities (PVHs) seen on T2 weighted MRI studies are common in elderly people and often represent demyelination of fibres. Damage to these fibres could lead to functional disconnection between brain regions. Electroencephalographic coherence, a measure of shared electrical activity between regions, was examined to determine if there was evidence for such disconnection. Twenty two subjects with clinically diagnosed dementia of the Alzheimer's type, 16 with multi-infarct dementia, and 18 normal controls were studied. It was hypothesised that coherence between areas presumably linked by fibres that traverse the periventricular region would be decreased in subjects with PVHs, and that PVHs would have a stronger association with decreased coherence than clinical diagnosis. It was also hypothesised that coherence between areas presumably connected by long corticocortical tracts that are neuroanatomically separated from the ventricles would be low in patients with Alzheimer's disease because of pyramidal cell death in this group, but would not be affected by the presence of PVHs. Patients with PVHs in fact had lower coherence than those without PVHs in the pre-Rolandic and post-Rolandic areas, where connecting fibres traverse the periventricular region. There was no effect of PVHs, however, on coherence between areas separated by the Rolandic fissure that were connected by long corticocortical tracts; this coherence was lowest among the patients with Alzheimer's disease. These patterns of association suggest that coherence may detect different types of neurophysiological "disconnection," and may be sensitive to selective damage to different fibre pathways.
\end{abstract}

$(\mathcal{F}$ Neurol Neurosurg Psychiatry 1994;57:1347-1354)

Magnetic resonance imaging shows that deep white matter disease is prevalent in elderly people. These high signal lesions on T2 weighted MRI (so called hyperintensities) are most commonly located in the periventricular region (periventricular hyperintensities (PVHs)). ${ }^{12}$ They also are found in the subcortical white matter (deep white matter hyperintensities or DWMHs), with a combined prevalence of PVHs and DWMHs on MRI scanning of "normal" elderly people of 60-100\%. ${ }^{3}$ Similar lesions are seen on CT of elderly people, but with a much lower prevalence ${ }^{4}$; this difference probably reflects the higher sensitivity of MRI. ${ }^{5}$ Hypertension, diabetes, and other cerebrovascular risk factors are associated with the presence of these lesions, ${ }^{67}$ although they are not usually lacunar infarcts.

The PVHs represent increased water content of white matter. The most common neuropathological correlates are demyelination, gliosis, and loss of axons, ${ }^{68-11}$ reflecting damage to periventricular fibre tracts. ${ }^{1012} 13$ It is thought that PVHs are linked to risk factors for cerebrovascular disease (hypertension) through damage to small blood vessels, which leads to demyelination. ${ }^{21014-16}$ The periventricular region is a watershed area that is particularly susceptible to ischaemic damage and demyelination. ${ }^{14}$

Despite general agreement that the prevalence and severity of PVHs and DWMHs are affected by age and cerebrovascular risk factors, ${ }^{17-19}$ they are common in elderly people and are often viewed as clinically normal findings. This view is supported by reports that white matter hyperintensities are compatible with normal intellectual function ${ }^{2021}$ and by studies showing no association between the presence of these lesions and cognitive deficits in neurologically normal people. ${ }^{19}{ }^{21-23}$ There is evidence, however, that severe white matter disease disrupts cognitive functions in some people, ${ }^{4425}$ and that the volume of damaged tissue may be a critical factor. ${ }^{25-27}$ One could hypothesise that there are degrees of damage to fibre tracts caused by periventricular lesions, and that when lesions are sufficiently severe, they could cause a "disconnection syndrome" analogous to that described by Geschwind $^{28}$ in subjects with lesions affecting association pathways.

Quantitative electroencephalographic (QEEG), coherence may be a useful way to examine the functional significance of PVH lesions. Coherence is a measure of the functional connectivity between brain areas, and normally is high between areas that are functionally related. ${ }^{29}$ It is thought to be mediated by corticocortical and corticosubcortical fibres of different lengths and types ${ }^{29}{ }^{30}$ and has been shown to be affected by vascular or degenerative diseases in elderly people. ${ }^{3132}$ With a model in which we compared coherence between areas separated by the Rolandic fissure with areas in the pre-Rolandic or 
post-Rolandic region, we found significant differences in coherence among control subjects, those with Alzheimer's disease, and those with multi-infarct dementia. ${ }^{33}$ In frequency bands above $6 \mathrm{~Hz}$, we found that the two groups of demented patients had different and relatively selective decreases in coherence. We hypothesised that these were due to damage to different fibre systems. We considered that patients with Alzheimer's disease had prominent decreases in trans-Rolandic coherence because of selective damage to long corticocortical tracts, whereas patients with multi-infarct dementia had prominent decreases in pre-Rolandic or post-Rolandic coherence because of damage to complex fibre networks in prefrontal and visual cortex association pathways respectively. There is neuropathological evidence to support these hypotheses. Patients with Alzheimer's disease have selective disconnection of long corticocortical fibres because of pyramidal cell death, ${ }^{34-38}$ and patients with multi-infarct dementia have prominent damage to preRolandic and post-Rolandic association fibre pathways because of periventricular tissue destruction. ${ }^{39} 41$

In the frequency band below $6 \mathrm{~Hz}$, patients with multi-infarct dementia showed decreased coherence, consistent with fibre damage. Interestingly, however, patients with Alzheimer's disease showed increased coherence in this frequency band. This increased coherence was statistically significant in the pre-Rolandic region, and there was a trend towards significance in the post-Rolandic region. ${ }^{33} \mathrm{We}$ previously speculated that the increased low frequency coherence in patients with Alzheimer's disease reflected basal ganglia dysfunction. This is consistent with knowledge regarding the EEG effects of deep grey matter dysfunction, which is known to cause projected slow wave activity synchronised over a wide area, ${ }^{42}$ and may be responsible for the diffuse slow wave activity seen in the EEGs of patients with Alzheimer's disease. Furthermore, the slow waves in Alzheimer's disease are believed to arise from degeneration in deep grey structures that provide cholinergic afferents to the cortex..$^{43} \mathrm{We}$ have found empirical evidence for the role of the basal ganglia in causing increased coherence from the study of patients with AIDS, in whom we detected increased coherence that had strong linear correlations with increased metabolism of basal ganglia. ${ }^{44}$

We postulated that if decreased coherence is an indicator of disruption in white matter tracts, it should be strongly and specifically related to the type of fibre damage. In patients with Alzheimer's disease, the most prevalent pathology is senile plaques in layers II, III, and $\mathrm{V}$ of the association cortex, damaging the origins and terminations of long corticocortical fibre tracts. ${ }^{34}$ In multi-infarct dementia, the most prevalent pathology is deep white matter demyelination in the periventricular region. ${ }^{40} 45$ Damage to long corticocortical tracts is relatively specific for Alzheimer's disease; whereas some senile plaques are found in normal elderly people, they are found in high concentrations in the association cortex only in patients with Alzheimer's disease. ${ }^{46}$ Conversely, damage to pre- or post-Rolandic networks should be seen in elderly subjects in general; prominent PVHs are a non-specific finding seen commonly in patients with Alzheimer's disease ${ }^{47}$ and multi-infarct dementia, ${ }^{40}$ as well as normal controls. ${ }^{3}$

Based on this postulate, we performed this study to test three hypotheses. Firstly, we postulated that decreased coherence in the postRolandic region would be more strongly associated with the presence of posterior PVHs than with clinical diagnosis in all subjects. The complex networks subserving projections of the visual pathways are dependent on periventricular white matter fibres, ${ }^{41}$ and should be vulnerable to disconnection by periventricular demyelination in normal people as well as those with Alzheimer's disease and multi-infarct dementia.

Secondly, we hypothesised that preRolandic coherence would be more strongly associated with the presence of anterior PVHs than with clinical diagnosis. Specifically, we predicted that anterior PVHs would be associated with decreased pre-Rolandic coherence in patients with multi-infarct dementia and in control subjects, and that it would militate against the increased pre-Rolandic coherence in low frequency bands in those with Alzheimer's disease. If subcortical grey and white matter are viewed as two components of a subcortical "circuit," and if increased coherence in patients with Alzheimer's disease is due to subcortical grey dysfunction, it should be opposed by the presence of PVHs, which would indicate damage to the subcortical white matter tracts.

Thirdly, we postulated that decreased trans-Rolandic coherence would be strongly associated with clinical diagnosis (lowest in the Alzheimer's disease group), but that there would be no association between decreased trans-Rolandic coherence and the presence of PVHs. Trans-Rolandic coherence presumably is mediated by long corticocortical tracts such as the superior longitudinal fasciculus, which are damaged by senile plaques in layers II, III, and $\mathrm{V}$ of the association cortex. By contrast with PVHs, this neuropathology is most common in those with a clinical diagnosis of Alzheimer's disease. Furthermore, the superior longitudinal fasciculus tract courses only through subcortical white matter and is wellseparated from the ventricles, ${ }^{41}$ and so, by contrast with the projections of prefrontal and visual pathways, should not be vulnerable to PVHs.

\section{Methods}

\section{SUBJECT SELECTION}

Fifty six persons (22 with Alzheimer's disease, 16 with multi-infarct dementia, and 18 normal controls) were examined in this study. The three groups were of comparable mean ages (72.6 (SD 7.2), $78(6 \cdot 2)$, and $73.6(7 \cdot 6)$ respectively), with a trend towards the patients 

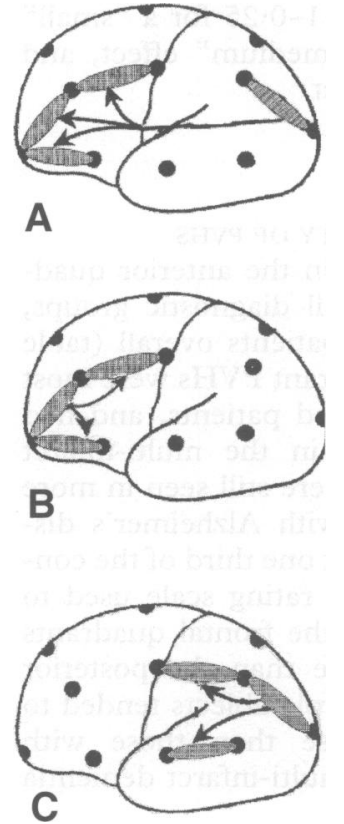

Electrode sites for mean coherence calculations. Shaded ellipses indicate bipolar electrode recording channels and arrows signify combinations of channels from which coherence was calculated and averaged. Electrode combinations are shown from the left hemisphere for (A) fascicle, (B) frontal, and $(C)$ visual electrode combinations; homologous electrodes were used for the right hemisphere. This is a modified reprint of fig 1 from Leuchter et al ${ }^{33}$ with permission of Oxford University Press. with Alzheimer's disease being slightly older than the patients with Alzheimer's disease ( $p$ $=0.07$ ). There were slightly more men than women in the Alzheimer's disease and multiinfarct dementia groups (M:F sex ratios of 0.57 and 0.6 , respectively), and slightly more women than men in the control group (ratio of 1.57). These persons were diagnosed and selected according to criteria previously described, ${ }^{32}{ }^{33}$ and the criteria are presented only briefly here. All patients with Alzheimer's disease met DSM-III-R criteria for primary degenerative dementia of the Alzheimer's type; they had dysfunction in at least two spheres of cognition, and Hachinski ischaemia scale (HIS) scores of $<4$. Patients with multiinfarct dementia met DMS-III-R criteria for multi-infarct dementia, and had HIS scores of 7 or greater or clear evidence of stroke. The subjects with dementia had undergone MRI of the brain as part of their routine clinical evaluation. Control subjects were free of any medical illness or medication known to appreciably affect CNS function, and MRI was performed for research purposes only. Patients with Alzheimer's disease or multi-infarct dementia had mini mental state examination (MMSE) scores lower than the control subjects $(18 \cdot 7,15 \cdot 7$, and 28.7 respectively), but the two groups of demented patients did not differ significantly from each other on this measure.

\section{QUANTITATIVE EEG RECORDINGS}

Recordings were performed by qualified technicians using recording techniques and filter settings previously described. ${ }^{32} 33$ Data were recorded at a sampling rate of 128 samples/ channel/s in four-second epochs, and subjects were alerted frequently to eliminate drowsiness. Data were reviewed by a technician who eliminated segments contaminated by eye movement, muscle, or other artifact. The first nine epochs (36 seconds) of data were selected for further analysis.

Spectral analysis was performed with the FACT system, which is based on the fast Fourier transform, and coherence was calculated as described previously. ${ }^{32}{ }^{33} \mathrm{Log}$ transformed coherence values from specific pairings of bipolar EEG channels were averaged together (as shown in the figure and listed in detail previously). ${ }^{33}$ These combinations approximate to the surface distribution of major neuroanatomical tracts, and the coherence from these combinations is presumably mediated through the different fibre pathways. Pre-Rolandic coherence was assessed with a measure called frontal, which was designed to cover the cortical areas receiving projections from the prefrontal cortex. Post-Rolandic coherence was assessed using the visual measure, designed to cover the projections of the visual pathways. TransRolandic coherence was assessed using the fascicle measure, which covered the cortical areas within the rostral projections of the superior longitudinal fasciculus. These averaged measures have been described previously, ${ }^{33}$ and the figure shows them graphically.
MAGNETIC RESONANCE IMAGING

T2 weighted spin echo transaxial images were obtained with TR of 1800-3000, and TE of 80-100, using either a Fonar 0.35 tesla (Fonar B-3000, Melville, NY, USA) or GE 1.5 tesla (General Electric Signa, Milwaukee, WI, USA) whole body scanner. Transaxial views showing the body or horns of the lateral ventricles were examined. Scans were rated jointly by two neuroradiologists (RBL and YA) who discussed each case and achieved a consensus rating of PVHs. The lateral ventricles were divided into two segments that were rated separately. These segments (anterior and posterior body) were defined on a transaxial image showing the body of the ventricles, with a transverse line placed through the body of the ventricles midway between the anterior and posterior ventricular margins. The posterior segment included the posterior horn, rated on a transaxial slice showing the most caudal extension of the posterior horn. We rated PVHs on a sector basis (right and left, anterior and posterior) as follows: $0=$ absent PVHs; $1=$ "pencil-thin" lining ( $<3$ $\mathrm{mm}$ ) along the body of the ventricles that is sometimes discontinuous, or slight "capping" at the horns; $2=$ "thick" lining (3-5 mm) along the ventricular margin that is usually continuous, and sometimes marked by slight extension into surrounding white matter; and, 3 = "prominent" lining $(>5 \mathrm{~mm})$ along the ventricular margin, with significant extension into surrounding white matter.

\section{COHERENCE AND MRI ASSOCIATIONS}

We calculated the mean coherence values for each coherence measure (frontal, visual, and fascicle) in each of the three diagnostic groups, and then separately for subgroups divided according to the presence or absence of white matter disease. For example, right and left frontal coherence was calculated for all patients with Alzheimer's disease and multi-infarct dementia, and control subjects, and then for groups with and without PVHs in the right and left frontal quadrants. The same analysis was performed for visual coherence and the posterior quadrants, and for fascicle coherence with both the anterior and posterior quadrants. We then used analysis of variance (ANOVA) to examine the significance of differences in mean coherence. We performed a series of six 2 (PVHspresent/absent) $\times 3$ (clinical diagnosis) ANOVAs with right and left frontal, visual, and fascicle coherence as dependent variables. We examined the effects of the two types of white matter lesions on coherence for all subjects, and for the three diagnostic groups separately. Analyses were performed with frontal coherence in the $4 \mathrm{~Hz}$ band, visual coherence in the $12 \mathrm{~Hz}$ band, and fascicle coherence in the $16 \mathrm{~Hz}$ band. Although other bands might also have shown the effects of white matter lesions, these frequency bands were the only ones examined in this study. In our previous report, these bands showed the most robust intergroup differences, and were most useful in the differential 
Table 1 Prevalence of periventricular white matter lesions by location and diagnostic group

\begin{tabular}{lllll}
\hline Location & Controls & $\begin{array}{l}\text { Alzheimer's } \\
\text { disease }\end{array}$ & $\begin{array}{l}\text { Multi-infarct } \\
\text { dementia }\end{array}$ & Overall \\
\hline Right anterior & $14 / 18(78)$ & $18 / 22(82)$ & $12 / 16(75)$ & $44 / 56(79)$ \\
Left anterior & $14 / 18(78)$ & $14 / 22(64)$ & $11 / 16(69)$ & $43 / 56(77)$ \\
Right posterior & $5 / 18(28)$ & $15 / 22(68)$ & $12 / 16(75)$ & $32 / 56(57)$ \\
Left posterior & $7 / 18(39)$ & $17 / 22(77)$ & $12 / 16(75)$ & $36 / 56(64)$ \\
\hline
\end{tabular}

Values in parentheses are $\%$.

Table 2 Median lesion severity ratings by quadrant and diagnostic group periventricular hyperintensities

\begin{tabular}{lllll}
\hline Quadrant & Controls & $\begin{array}{l}\text { Alzheimer's } \\
\text { disease }\end{array}$ & $\begin{array}{l}\text { Multi-infarct } \\
\text { dementia }\end{array}$ & Overall \\
\hline Right anterior & $1(1-2)$ & $1(1-2)$ & $1(0 \cdot 5-1 \cdot 5)$ & $1(1-1)$ \\
Left anterior & $1(1-1)$ & $1(1-1)$ & $1(0-1 \cdot 5)$ & $1(1-1)$ \\
Right posterior & $0(0-1)$ & $1(0-1)$ & $1(0 \cdot 5-1 \cdot 5)$ & $1(0-1)$ \\
Left posterior & $0(0-1)$ & $1(1-1)$ & $1(0 \cdot 5-2)$ & $1(0-1)$ \\
Overall & $0 \cdot 5(0 \cdot 5-1)$ & $1(0 \cdot 5-1 \cdot 75)$ & $1(0 \cdot 8-1 \cdot 4)$ & $1(0 \cdot 5-1 \cdot 1)$ \\
\hline
\end{tabular}

Table 3 Mean (SD) of frontal coherence by clinical diagnosis and PVHs

\begin{tabular}{|c|c|c|c|}
\hline \multirow[b]{2}{*}{ Clinical diagnosis } & \multirow[b]{2}{*}{$\begin{array}{l}\text { Total } \\
(n=56)\end{array}$} & \multicolumn{2}{|l|}{ PVHs } \\
\hline & & $\begin{array}{l}\text { Absent } \\
(n=13)\end{array}$ & $\begin{array}{l}\text { Present } \\
(n=43)\end{array}$ \\
\hline \multicolumn{4}{|l|}{ Left frontal coherence: } \\
\hline Control & $0 \cdot 15(0 \cdot 167)$ & $0.25(0 \cdot 16)$ & $0 \cdot 13(0 \cdot 16)$ \\
\hline Alzheimer's disease & $0.31(0.26)$ & $0.57(0.12)$ & $0.25(0.25)$ \\
\hline Multi-infarct dementia & $0.22(0.12)$ & $0.25(0.07)$ & $0.21(0.14)$ \\
\hline Total & $0.23(0.21)$ & $0.34(0.19)$ & $0 \cdot 20(0 \cdot 20)$ \\
\hline \multicolumn{4}{|l|}{ Right frontal coherence: } \\
\hline Control & $0.23(0.17)$ & $0.32(0.16)$ & $0 \cdot 20(0 \cdot 18)$ \\
\hline Alzheimer's disease & $0.36(0.25)$ & $0.63(0.19)$ & $0.29(0.22)$ \\
\hline Multi-infarct dementia & $0.32(0.12)$ & $0.32(0.19)$ & $0.31(0.09)$ \\
\hline Total & $0 \cdot 30(0 \cdot 20)$ & $0.42(0.22)$ & $0.27(0.18)$ \\
\hline
\end{tabular}

Table 4 Relation between frontal coherence, periventricular hyperintensities, and clinical diagnosis

\begin{tabular}{llrll}
\hline Effect & $S S$ & $d f$ & $F$ & $p$ Value \\
\hline Left frontal coherence: & & & & \\
Clinical diagnosis & 0.22 & 2 & 3.31 & 0.04 \\
PVHs & 0.26 & 1 & 7.82 & 0.007 \\
PVHs $\times$ clinical diagnosis & 0.15 & 2 & 2.26 & 0.11 \\
Residual & 1.66 & 50 & & \\
Right frontal coherence: & & & & \\
Clinical diagnosis & 0.17 & 2 & 2.56 & 0.09 \\
PVHs & 0.23 & 1 & 6.90 & 0.01 \\
PVHs $\times$ clinical diagnosis & 0.19 & 2 & 2.89 & 0.06 \\
Residual & 1.66 & 50 & & \\
\hline
\end{tabular}

Table 5 Mean (SD) of visual coherence

\begin{tabular}{|c|c|c|c|}
\hline \multirow[b]{2}{*}{ Clinical diagnosis } & \multirow[b]{2}{*}{$\begin{array}{l}\text { Total } \\
(n=56)\end{array}$} & \multicolumn{2}{|l|}{$P V H s$} \\
\hline & & $\begin{array}{l}\text { Absent } \\
(n=20)\end{array}$ & $\begin{array}{l}\text { Present } \\
(n=36)\end{array}$ \\
\hline \multicolumn{4}{|l|}{ Left visual coherence: } \\
\hline Control & $0.54(0 \cdot 19)$ & $0.57(0 \cdot 19)$ & $0.48(0.18)$ \\
\hline Alzheimer's disease & $0.51(0.25)$ & $0.68(0.12)$ & $0.46(0.26)$ \\
\hline Multi-infarct dementia & $0.23(0.25)$ & $0.33(0.34)$ & $0.28(0.23)$ \\
\hline Total & $0.46(0.25)$ & $0.55(0.23)$ & $0.41(0.24)$ \\
\hline \multicolumn{4}{|l|}{ Right visual coherence: } \\
\hline Control & $0.47(0.27)$ & & \\
\hline Alzheimer's disease & $0.50(0.26)$ & & \\
\hline Multi-infarct dementia & $0.35(0.26)$ & & \\
\hline Total & $0.45(0.27)$ & & \\
\hline
\end{tabular}

Where there was no effect of PVHs, data are reported only for the diagnostic groups.

diagnoses of Alzheimer's disease and multiinfarct dementia. ${ }^{33}$

We compared the strength of the association between PVHs and clinical diagnosis with coherence by calculating effect sizes as described by Cohen. ${ }^{48}$ We used the recom- mended definitions of $0 \cdot 1-0 \cdot 25$ for a "small" effect, $0.25-0.4$ for a "medium" effect, and $>0.40$ for a "large" effect.

\section{Results}

PREVALENCE AND SEVERITY OF PVHS

The presence of PVHs in the anterior quadrants was common in all diagnostic groups, seen in nearly $80 \%$ of patients overall (table 1). In the posterior quadrant PVHs were most common in the demented patients, and had the highest prevalence in the multi-infarct dementia group. They were still seen in more than half the patients with Alzheimer's disease, however, and about one third of the controls. On the four point rating scale used to rate severity of lesions, the frontal quadrants had more severe disease than the posterior quadrants, and the control subjects tended to have less severe disease than those with Alzheimer's disease or multi-infarct dementia (table 2).

ASSOCIATIONS BETWEEN FRONTAL OR VISUAL COHERENCE, PVHS, AND CLINICAL DIAGNOSIS Frontal coherence was highest in the Alzheimer's disease group, with the multiinfarct dementia group having a slightly lower level and the control group the lowest level (table 3 ). These group differences were significant in the left frontal region; there was a trend towards significance in the right frontal region (table 4).

The presence of PVHs had a large effect on the magnitude of frontal coherence (effect sizes for PVHs on left and right frontal coherence of 0.41 and 0.42 respectively); there was a medium effect of clinical diagnosis on frontal coherence (effect sizes for diagnosis of 0.30 and 0.27 in the left and right respectively). The groups in which PVHs were present consistently had lower coherence than those without PVHs (table 3). There was a greater than $50 \%$ reduction in coherence in the Alzheimer's disease group, a greater than $30 \%$ reduction in the control group, and greater than $15 \%$ reduction in the multiinfarct dementia group (in left frontal coherence only) associated with the presence of PVHs. Subcategorisation of subjects within a diagnostic group according to the presence or absence of PVHs significantly altered the pattern of coherence differences between diagnostic groups. For example, the patients with Alzheimer's disease without PVHs had coherence values about twice those of patients with multi-infarct dementia without PVHs; patients with Alzheimer's disease with PVHs, however, had lower coherence values that were comparable with those of the multiinfarct dementia group with PVHs. When present, PVHs affected all diagnostic groups similarly, although the interaction term approached significance at the $10 \%$ level (table 4).

Different findings were seen for the left visual coherence measure, although similar trends emerged. Overall, the multi-infarct dementia group had coherence that was lower 
Table 6 Relation between visual coherence, PVHs, and clinical diagnosis

\begin{tabular}{llrll}
\hline Effect & $S S$ & $d f$ & $F$ & $p$ Value \\
\hline Left visual coherence: & & & & \\
$\quad$ Clinical diagnosis & 0.62 & 2 & 6.03 & 0.005 \\
PVHs & 0.17 & 1 & 3.31 & 0.08 \\
PVHs $\times$ clinical diagnosis & 0.06 & 2 & 0.54 & 0.59 \\
Residual & 2.55 & 50 & & \\
Right visual coherence: & & & & \\
Clinical diagnosis & 0.21 & 2 & 1.39 & 0.26 \\
PVHs & 0.00 & 1 & 0.00 & 0.98 \\
PVHs $\times$ clinical diagnosis & 0.001 & 2 & 0.00 & 0.99 \\
Residual & 3.70 & 50 & & \\
\hline
\end{tabular}

Table 7 Means (SD) of fascicle coherence

\begin{tabular}{ll}
\hline Clinical diagnosis & Total $(n=56)$ \\
\hline Left fascicle coherence: & $0 \cdot 21(0 \cdot 18)$ \\
Control & $0.02(0 \cdot 26)$ \\
Alzheimer's disease & $0.11(0 \cdot 14)$ \\
Multi-infarct dementia & $0.09(0 \cdot 22)$ \\
Total & $0 \cdot 18(0 \cdot 16)$ \\
Right fascicle coherence: & $0.04(0 \cdot 15)$ \\
Control & $0 \cdot 10(0 \cdot 17)$ \\
Alzheimer's disease & $0 \cdot 10(0 \cdot 16)$ \\
Multi-infarct dmentia & \\
Total &
\end{tabular}

As there was no effect of PVHs, data are reported only for the diagnostic groups.

than the Alzheimer's disease and control groups; the subgroups of those with PVHs had mean coherence that was $16-30 \%$ lower than subgroups without PVHs (table 5). The effect of PVHs approached significance at the $5 \%$ level, and the effect of clinical diagnosis was statistically significant (table 6). The PVHs had a medium effect size for left visual coherence $(0 \cdot 30)$, whereas clinical diagnosis had a large effect size $(0 \cdot 47)$. Neither clinical diagnosis nor PVHs had a significant effect on coherence in the right hemisphere (table 6).

There was no effect of the severity of PVHs on frontal or visual coherence measures in any brain region (data not presented).

ASSOCIATIONS BETWEEN FASCICLE COHERENCE, PVHS, AND CLINICAL DIAGNOSIS

Patients with Alzheimer's disease had the lowest coherence of all diagnostic groups in the fascicle measure (table 7). There was a strong effect of clinical diagnosis on fascicle coherence from both the left and right hemispheres,

Table 8 Relation between fascicle coherence, anterior PVHs, posterior PVHs, and clinical diagnosis

\begin{tabular}{|c|c|c|c|c|}
\hline Effect & $s S$ & $d f$ & $F$ & p Value \\
\hline $\begin{array}{l}\text { Left fascicle coherence: } \\
\text { Clinical diagnosis } \\
\text { Anterior PVHs } \\
\text { Anterior PVHs } \times \text { clinical diagnosis } \\
\text { Residual }\end{array}$ & $\begin{array}{l}0 \cdot 46 \\
0 \cdot 08 \\
0 \cdot 01 \\
2 \cdot 05\end{array}$ & $\begin{array}{r}2 \\
1 \\
2 \\
50\end{array}$ & $\begin{array}{l}6 \cdot 04 \\
1 \cdot 87 \\
0 \cdot 14\end{array}$ & $\begin{array}{l}0 \cdot 005 \\
0 \cdot 18 \\
0 \cdot 87\end{array}$ \\
\hline $\begin{array}{l}\text { Posterior PVHs } \\
\text { Posterior PVHs } \times \text { clinical diagnosis } \\
\text { Residual }\end{array}$ & $\begin{array}{l}0 \cdot 02 \\
0 \cdot 02 \\
2 \cdot 10\end{array}$ & $\begin{array}{r}1 \\
2 \\
50\end{array}$ & $\begin{array}{l}0.44 \\
0.24\end{array}$ & $\begin{array}{l}0.51 \\
0.79\end{array}$ \\
\hline $\begin{array}{l}\text { Right fascicle coherence: } \\
\text { Clinical diagnosis } \\
\text { Anterior PVHs } \\
\text { Anterior PVHs } \times \text { clinical diagnosis } \\
\text { Residual }\end{array}$ & $\begin{array}{l}0.21 \\
0.06 \\
0.06 \\
1 \cdot 24\end{array}$ & $\begin{array}{r}2 \\
1 \\
2 \\
50\end{array}$ & $\begin{array}{l}4 \cdot 16 \\
2 \cdot 27 \\
1 \cdot 10\end{array}$ & $\begin{array}{l}0 \cdot 02 \\
0 \cdot 14 \\
0 \cdot 34\end{array}$ \\
\hline $\begin{array}{l}\text { Posterior PVHs } \\
\text { Posterior PVHs } \times \text { clinical diagnosis } \\
\text { Residual }\end{array}$ & $\begin{array}{l}0.07 \\
0.07 \\
1 \cdot 21\end{array}$ & $\begin{array}{r}1 \\
2 \\
50\end{array}$ & $\begin{array}{l}2.95 \\
1.39\end{array}$ & $\begin{array}{l}0.19 \\
0.26\end{array}$ \\
\hline
\end{tabular}

but PVHs had no significant association with decreased fascicle coherence (table 8). There was no effect of the severity of PVHs on fascicle coherence measures in the right or left hemisphere (data not presented).

\section{Discussion}

These findings partially support our first two hypotheses, indicating that decreased coherence measured over prefrontal or visual cortex association networks is associated statistically with damage to fibres in the periventricular white matter. In testing the first hypothesis, we found that mean coherence in the left visual measure was lower when PVHs were present in the left posterior quadrant in the three groups, and there was a trend towards this effect being statistically significant. The effect of PVHs, however, was not as strong as that of clinical diagnosis. In the right visual measure, there was no effect of either PVHs or clinical diagnosis.

Results of coherence analyses from preRolandic regions were entirely consistent with our second hypothesis. Those with PVHs in the anterior quadrants had lower frontal coherence than those without PVHs, regardless of the diagnostic group. Among the patients with Alzheimer's disease, those with PVHs had lower low frequency coherence than those without PVHs. This finding is consistent with the hypothesis that PVHs oppose increased coherence resulting from basal ganglia dysfunction, through damage to white matter tracts mediating coherence. Even the control subjects with anterior PVHs had lower frontal coherence than those without, although the difference reached statistical significance only when all groups were pooled. The effect of PVHs was greater than that of clinical diagnosis on left and right frontal coherence.

It is unclear why the effects of anterior and left sided PVHs were notably greater than those of posterior and right sided PVHs on coherence. There are several possible explanations. Firstly, both the prevalence and severity of anterior PVHs were greater than those for posterior PVHs in this sample. This difference is due in part to the control subjects, in whom posterior PVHs were much less common and more mild. Secondly, earlier work by Tucker and colleagues ${ }^{49}$ suggests that the fibres mediating coherence in the right hemisphere have a more diffuse organisation than those from the left hemisphere. This diffuse fibre structure could help protect the functional connections in the right hemisphere from the effects of periventricular white matter disease. Thirdly, the post-Rolandic fibres of the visual association pathway are not solely periventricular, but sweep broadly through the subcortical white matter. ${ }^{41}$ This broad lateral extension of the fibres in the post-Rolandic region may spare many of the fibres helping to mediate functional connections.

These results show an association between PVHs and decreased coherence, but they do not prove a causal relation. Furthermore, 
there were two unexpected results that raise doubts about the strength of a causal link. Firstly, we did not detect an effect of severity of PVHs on coherence in any region. Secondly, the multi-infarct dementia group, in whom neuropathological studies suggest that PVHs should be prominent, did not show the largest decrease in coherence in the presence of PVHs. These results indicate that PVHs are not the only factor that could lead to decreased coherence in these subjects. Other factors could include cortical or deep grey matter damage and demyelination of subcortical white matter.

These unexpected results could also reflect the relatively crude methods used to assess the severity of PVHs. Our visual inspection of MRIs may not have accurately reflected the severity of white matter disease, and PVHs that we defined as "mild" may have been sufficiently severe to cause maximal disruption of connections. This possibility is consistent with the high vulnerability of periventricular white matter to ischaemic damage. It is a watershed area supplied exclusively by fine perforating blood vessels branching from arterioles at the cortical surface. ${ }^{41}$ As a result, the periventricular white matter is the primary area damaged whenever there is appreciable cerebrovascular disease, showing demyelination and cell loss. ${ }^{40} 45$ Our rating scales therefore may not have been sufficiently sensitive or accurate to detect a severity effect. Volumetric estimates of white matter damage on a larger number of subjects may be required to elucidate the relation between severity of PVHs and decreased coherence.

We do find support for a causal link between PVHs and decreased coherence in the testing of our third hypothesis. We found that diagnosis but not PVHs had a strong association with decreased fascicle coherence. This finding supports our model in which preRolandic and post-Rolandic coherence measurements are selectively sensitive to periventricular neuropathology. Because the long corticocortical fibres crossing the Rolandic fissure (tracts such as the superior longitudinal fasciculus) are well separated from the periventricular region, damage in this region should not affect coherence mediated by long fibre tracts. Instead, the long corticocortical fibres that link the pre-Rolandic and post-Rolandic regions should be systematically damaged at a microscopic level, by pathology that is most common in the Alzheimer's disease diagnostic group and not detectable by MRI.

Overall, these results support a model in which periventricular white matter disease leads to functional disconnection between certain brain regions, and coherence detects this disconnection. When the pathology hypothesised to affect a measure was not specific for a single diagnostic group (as with PVHs and frontal coherence), the decreased coherence was best explained by grouping subjects according to the presence or absence of pathology. When the pathology that was hypothesised to affect a measure was specific for a single diagnosis (as with senile plaques and fascicle coherence), however, the decreased coherence was best explained by grouping subjects according to clinical diagnosis.

White matter lesions could cause disconnection between brain regions through damage to afferent fibres (deafferentation), as PVHs are commonly caused by demyelination of white matter tracts. An association between the lesions and deafferentation is consistent with recent results showing that the lesions are associated with the EEG slowing in the elderly ${ }^{50}$; pathological slowing is known to be caused by partial cortical deafferentation. ${ }^{51}$ Elderly patients with extensive demyelination in the white matter show not only slowed processing speed, but also prolonged central conduction time on evoked potentials, ${ }^{52} 53$ both of which have been interpreted as indicating that deafferentation may be clinically significant. ${ }^{54}$ There is reason to believe that PVHs may be more likely than DWMHs to cause significant cortical deafferentation. The PVHs occur in a critical neuroanatomical area where fibres that link key areas within the prefrontal or postRolandic associative pathways are known to course. $^{41}$

These findings are also consistent with an increasing body of evidence that white matter disease is not a benign finding in elderly people, and may indicate subclinical brain disease. ${ }^{424} 25$ In carefully chosen elderly subjects without risk factors, the prevalence of PVHs or DWMHs is low, ${ }^{55}$ and it reaches its highest severity and prevalence in patients with dementia. $^{3}$ Recent studies confirm that regardless of the clinical diagnostic group, the presence of these lesions is associated with diminished perfusion. Kawamura and colleagues $^{56}$ used CT densitometry to detect white matter loss in normal elderly people and those with Alzheimer's disease. They found similarly decreased perfusion in areas of white matter damage in both groups, although the total volume of damaged tissue was greater in the patients with dementia. Meguro and coworkers 9 studied 21 normal subjects with PVHs and found global decreases in blood flow, but not oxygen utilisation, that were correlated with the severity of PVHs. Other investigators have found an increased prevalence of primitive reflexes in normal elderly people with white matter lesions ${ }^{57}$ as well as a slowing of processing speed. ${ }^{54}$

Although EEG, blood flow, and other clinical studies indicate that white matter lesions are functionally significant, the significance of these lesions for cognitive function remains unclear. As mentioned earlier, most studies have not detected an effect of hyperintensities on cognition in neurologically normal subjects. ${ }^{19} 21-23$ Severe white matter disease, however, is associated with cognitive dysfunction: the more severe disease detected by CT (but not $M R I)$ is associated with cognitive losses, ${ }^{424}$ and the more severe lesions seen in patients with dementia predict the level of impairment. ${ }^{58-60}$ Two studies ${ }^{26} 27$ found that some subjects seemed to have losses related to 
lesions. Boone and colleagues ${ }^{25}$ found, in a quantitative MRI study of more than 100 "normal" subjects, that those with lesion areas $>10 \mathrm{~cm}^{2}$ had "substantial" disturbances on selected tests (primarily of frontal function). These findings raise the possibility of a "threshold effect" in which only more severe disease disrupts cognitive functions.

Our results may be interpreted as showing that coherence detects a spectrum of neurophysiological "disconnection" in elderly people, that may have a neuroanatomical basis. In this construct, disconnection is defined as either degeneration or demyelination of a known set of fibres linking cortical regions. The construct of neurophysiological disconnection is consistent with Geschwind's clinical descriptions, as well as with Cummings' and Benson's clinical construct of "cortical" and "subcortical" dementia, distinguished by the "major associated neuroanatomical involvement" and clustering of neuropsychological symptoms. ${ }^{61}$ Cortical dementias (such as Alzheimer's disease) are marked by disconnection at the level of the cortex (degeneration of pyramidal cells in laminae II, III, and V). Dementias that are primarily subcortical, such as multi-infarct dementia, are marked by disconnection at the level of the periventricular white matter (demyelination of white matter tracts).

Coherence may enhance the specificity of the clinical evaluation in identifying loci of cortical and subcortical neuropathology. As it is based on a physiological measure of the interaction between brain regions, rather than solely on clinical observation or performance tests, it yields quantitative measurements of the degree of disconnection of white matter tracts occurring at the cortical or subcortical level. This detailed information may be particularly useful for cases where both cortical and subcortical damage are present, such as in "mixed" dementias where current clinical methods may not detect the coexistence of pathology. ${ }^{6263}$ Further evaluation of the disconnection construct is necessary, however, before these coherence results can be assigned a clear physiological and structural interpretation. We detected decreased coherence in two specific types of electrode combinations. Other combinations of electrodes, corresponding to the surface distributions of other neuroanatomical tracts (such as interhemispheric tracts), should be examined to extend the validity of this model. Larger numbers of subjects should be examined, including those with other diseases in which white matter disease is prominent (for example, leukodystrophies, multiple sclerosis), because other white matter diseases should yield comparable results. More complex models of coherence should also be examined, including factors such as total grey or white matter volume, as lesion volume alone explains only a portion of the variance in coherence.

Ultimately, the potential usefulness of the disconnection construct may rest on demonstrating the relevance of changes in coherence to cognitive function as measured by neuro- psychological testing. For example, it would be useful to examine the relation between tests of visuospatial processing and visual coherence, or between general tests of right hemispheric function and right fascicle coherence. If there are associations between performance on cognitive tasks and coherence in brain regions that subserve those cognitive functions, coherence may be both a specific and highly useful indicator of brain dysfunction.

We gratefully acknowledge the assistance of Michelle Abrams and Susan Rosenberg-Thompson, in compiling clinical information on these subjects, and Suzanne Hodgkin, Mariahn
Smith, and Ms Toni Robison, who collected and processed

Smith, and $M$

We are very grateful for the assistance of Valerie Gausche, Mary Ann Burns, Marco Favilli, Tim Teachout, and $\mathbf{M r}$ Michael Gattuso, who assisted in scheduling and performing MRI and in the processing of MRI data.

We also thank Ms Vernita Hughes, who provided expert assistance in the preparation of the manuscript and figure.

This work was supported by grant MH 40705 from the National Institute of Mental Health (Dr Leuchter). Additional support was provided by the UCL Alsheimer's Disease support was provided by the UCLA Alzheimer's Disease Center grant P30 AG10123 from the National Institute on Aging, and by the Department of Veterans Affairs. The views necessarily represent those of the Department of Veterans necessa

1 Zimmerman RD, Fleming CA, Lee BCP, Saint-Louis LA, Deck MDF. Periventricular hyperintensity as seen by magnetic resonance: prevalence and significance. $A m \mathcal{F}$ magnetic resonance: prevalen

2 Coffey CE, Figiel GS, Djang WT, et al. Leukoeffey CE, Figiel GS, Djang WT, et al. Leuko-
encephalopathy in elderly depressed patients referred for encephalopathy in elderly depressed pate

3 Leuchter AF. Brain structural and functional correlates of late-life depression. In: Lebowitz B, Schneider L, eds. Diagnosis and treatment of depression in late life. Washington, DC: American Psychatric Press, 1994: 117-30.

4 Kobari M, Meyer JS, Ichijo M. Leuko-araiosis, cerebral atrophy, and cerebral perfusion in normal aging. Arch Neurol 1990;47:161-5.

5 Awad IA, Spetzler RF, Hodak JA, Awad CA, Williams F Jr. Incidental lesions noted on magnetic resonance imaging of the brain: prevalence and clinical significance in various age groups. Neurosurgery 1987;20:222-7.

6 Awad IA, Spetzler RF, Hodak JA, Awad CA, Carey R. Incidental subcortical lesions identified on magnetic resoncidental subcortical lesions identified on magnetic resonance imaging in the elderly. I. Correlations with age

7 Hachinski VC, Potter P, Merskey DM. Leuko-araiosis. Arch Neurol 1987;44:21-3.

8 Awad IA, Johnson PC, Spetzler RF, Hodak JA. Incidental subcortical lesions identified on magnetic resonance imaging in the elderly. II. Postmortem pathological correlations. Stroke 1986;17:1090-7.

9 Meguro K, Hatazawa J, Yamaguchi $\mathrm{T}$, et al. Cerebral circulation and oxygen metabolism associated with subclinical periventricular hyperintensity as shown by magnetic resonance imaging. Ann Neurol 1990;28:378-83.

10 Kirkpatrick JB, Hayman LA. White-matter lesions in MR imaging of clinically healthy brains of elderly subjects: imaging of clinically healthy brains of elderly subjects:

11 Grafton ST, Sumi SM, Stimac GK, et al. Comparison of post mortem magnetic resonance imaging and neupost mortem magnetic resonance imaging and neuNeurol 1991;48:293-8.

12 Kinkel WR, Jacobs L, Polachini I, Bates V, Heffner RR. Subcortical arteriosclerotic encephalopathy (Binswanger's disease): Computed tomographic nuclear magnetic resonance, and clinical correlations. Arch Neurol 1985;42:951-9.

13 Englund E, Brun A. White matter changes in dementia of Alzheimer's type: the difference in vulnerability between cell components. Histopathology 1990;16:433-9.

14 DeReuck J, Crevits L, DeCoster W, Sieben G, vander Eecken H. Pathogenesis of Binswanger chronic progressive subcortical encephalopathy. Neurology 1980;30: $920-8$

15 Gerard G, Weisberg LA. MRI periventricular lesions in adults. Neurology 1986;36:998-1001.

16 Coffey CE, Figiel GS, Djang WT, Weiner R. Subcortical hyperintensity on magnetic imaging: a comparison of normal and depressed elderly subjects. Am $\mathcal{F}$ Psychiatry normal and depresse

17 Inzitari D, Diaz F, Fox A, et al. Vascular risk factors and leukoariosis. Arch Neurol 1987;44:42-7.

18 Jernigan TL, Press GA, Hesselink JR. Methods for measuring brain morphologic features on magnetic resonance images. Arch Neurol 1990;47:27-32. 
19 Tupler LA, Coffey CE, Logue PE, Djang WT, Fagan SM. Neuropsychological significance of subcortical white matter hyperintensity. Arch Neurol 1992;49:1248-52.

20 Fein G, Van Dyke C, Davenport L, et al. Preservation of normal cognitive functioning in elderly subjects with extensive white-matter lesions of long duration. Arch Gen Psychiatry 1990;47:220-3.
extensive white-matter lesion

21 Austrom MG, Thompson RF, Hendrie HC. Foci of increased T2 signal intensity in MR images of healthy elderly subjects:

22 Brant-Zawadzki M, Fein G, Van Dyke C, et al. MR imag ing of the aging brain: patchy white matter lesions and dementia. Am $\mathcal{f}$ Neuroradiol 1985;6:675-82.

23 Schmidt R, Gazekas F, Offenbacher H. Magnetic resonance imaging white matter lesions and cognitive impairment in hypertensive individuals. Arch Neurol 1991;48:417-20.

24 Steingart A, Hachinski VC, Lau C, et al. Cognitive and neurologic findings in demented patients with diffuse white matter lucencies on computed tomographic scans (leuko-araiosis). Arch Neurol 1987;44:36-9.

25 Boone KB, Miller BL, Lesser IM, et al. Neuropsychological correlates of white-matter lesions in psychological correlates of white-matter lesions in 1992;49:549-54.

26 Bernardin LJ, Rao SM, Haughton VM, Yetkin ZF Ellington LE. The neuropsychological significance of leukoaraiosis in a hypertensive population. $\mathcal{f}$ Clin Exp Neuropsychol 1991;13:78-9.

27 Rao SM, Mittenberg W, Bernardin L, Haughton V, Leo GJ. Neuropsychological test findings in subjects with leukoaraiosis. Arch Neurol 1989;46:40-4.

28 Geschwind N. Disconnexion syndromes in animals and man. Part I. Brain 1965;138:237-94

29 Nunez PL. Electric fields in the brain: the neurophysics of $E E G$. New York: Oxford University Press, 1981.

30 Thatcher RW, Krause PJ, Hrybyk M. Cortico-cortical associations and EEG coherence: a two-compartmental model. Electroencephal Clin Neurophysiol 1986;64: 123-43.

31 O'Connor KP, Shaw JC, Ongley CO. The EEG and differential diagnosis in psychogeriatrics. $\mathrm{Br} \mathcal{F}$ Psychiatry 1979;135:156-62.

32 Leuchter AF, Spar JE, Walter DO, Weiner H Electroencephalographic spectra and coherence in the diagnosis of Alzheimer's-type and multi-infarct dementia: A pilot study. Arch Gen Psychiatry 1987;44:993-8.

33 Leuchter AF, Newton TF, Cook IA, et al. Changes in brain functional connectivity in Alzheimer-type and multi-infarct dementia. Brain 1992;115:1543-61

34 Morrison JH, Scherr S, Lewis DA, Campbell MJ, Bloom FE. The laminar and regional distribution of neocortical somatostatin and neuritic plaques: implications for Alzheimer's disease as a global neocortical disconnection syndrome. In: Scheibel A, Wechsler A, Brazier M, eds. The biological substrates of Alzheimer's disease. Orlando: Academic Press, 1986:115-31.

35 De Lacoste M-C, White CL III. The role of cortical connectivity in Alzheimer's disease pathogenesis: a review and model system. Neurobiology of Aging 1993;14:1-16.

36 Pearson RCA, Esiri MM, Hiorns RW, Wilcock GK Powell TPS. Anatomical correlates of the distribution of the pathological changes in the neocortex in Alzheimer the pathological changes in the neocortex in Alz

37 Esiri MM. Pearson RC, Powell TP. The cortex of the primary auditory area in Alzheimer's disease. Brain Research, Amsterdam 1986;366:385-7

38 Lewis DA, Campbell MJ, Terry RD, Morrison JH Laminar and regional distributions of neurofibrillary tangles and neuritic plaques in Alzheimer's disease: a quantitative study of visual and auditory cortices. f Neurosci 1987; 7:1799-808.

39 Roman GC. The identity of lacunar dementia and Binswanger disease. Med Hypotheses 1985;16:389-91.

40 Roman GC. Senile dementia of the Binswanger type: a vascular form of dementia in the elderly. Fournal of the American Medical Association 1987;258:1782-8.

41 Carpenter MB. Core text of neuroanatomy. Baltimore: Williams and Wilkins, 1972 .

42 Gloor $P$, Ball $G$, Schaul N. Brain lesions that produce delta waves in the EEG. Neurology 1977;27:326-33.

43 Buzsaki G, Bickford RG, Ponomareff G, et al. Nucleus basalis and thalamic control of neocortical activity in the freely moving rat. $\mathcal{F}$ Neurosci $1988 ; 8: 4007-26$.

44 Newton TF, Leuchter AF, Walter DO, et al. EEG coherence in men with AIDS: association with subcortical metabolic activity. Neuropsychia Clin Neurosci 1993;5 316-21.

45 Stuss DT, Cummings JL. Subcortical vascular dementias. In: Cummings JL, ed. Subcortical dementia. Oxford: Oxford University Press, 1990:145-63.

46 Kemper T. Neuroanatomical and neuropathological changes in normal aging and in dementia. In: Alber ML, ed. Clinical neurology of aging. New York: Oxford University Press, 1984:9-52.

47 Brun A. White-matter disease in the elderly demented. Bull Clin Neurosci 1988;53:125-7.

48 Cohen J. Statistical power analysis for the behavioral sciences. New Jersey: Lawrence Erlbaum Associates, Inc, 1988:284-7.

49 Tucker DM, Roth DL, Bair TB. Functional connections among cortical regions: topography of EEG coherence. Electroencephal Clin Neurophysiol 1986;63:242-50.

50 Oken, BS, Kaye JA. Electrophysiologic function in the healthy, extremely old. Neurology 1992;42:519-26.

51 Steriade M, Gloor $P$, Llinas RR, Lopes da Silva $\mathbf{F H}$ Mesulam M-M. Basic mechanisms of cerebral rhythmic activities. Electroencephal Clin Neurophysiol 1990;76: 481-508.

52 Abbruzzese G, Reni L, Cocito L, et al. Short-latency somatosensory evoked potentials in degenerative and vascular dementia. F Neurol Neurosurg Psychiatry 1984 47:1034-7.

53 Kato H, Sugawara Y, Ito H, Kogure K. White matter lucencies in multi-infarct dementia: a somatosensory
evoked potentials and CT study. Acta Neurol Scand 1990;81:181-3.

54 Junque C, Pujol J, Vendrell P, et al. Leuko-araiosis on magnetic resonance imaging and speed of mental promagnetic resonance imaging and sp

55 Wahlund L-O, Agartz I, Almqvist $\mathrm{O}$, et al. The brain in healthy aged individuals: MR imaging. Radiology 1990; 174:675-9.

56 Kawamura J, Meyer JS, Terayama Y, Weathers S. Leukoariosis and cerebral hypoperfusion compared in elderly normals and Alzheimer's dementia. $₹ \mathrm{Am}$ Geriatr Soc $1992 ; 4: 375-80$.

57 Kobayaschi S, Yamaguchi S, Okada K, Yamashita K. Primitive reflexes and MRI findings, cerebral blood flow in normal elderly. Gerontology 1990;36:199-205.

58 Bondareff W, Raval J, Colletti PM, Hauser DL Quantitative magnetic resonance imaging (MRI) and the severity of dementia in Alzheimer's disease. $A m f$ Psychiatry 1988;145:853-8.

59 Bondareff W, Raval J, Woo B, Houser DL, Colletti PM Magnetic resonance imaging and the severity of dementia Magnetic resonance imaging and the severity of deme

60 Almqvist O, Wahlund LO, Anderson-Lundman G Backman L. White-matter changes assessed by MRI and neuropsychological functions in demented and healthy aged. Fifth congress of the international psychogeriatric association; book of abstracts. Rome, Italy, 1991:26.

61 Cummings JL, Benson DF. Dementia: a clinical approach. Boston: Butterworths, 1983.

62 Ettlin TM, Staehelin H, Kischka U, et al. Computed tomography, electroencephalography, and clinical features in the differential diagnosis of senile dementia. Arch Neurol 1989;46:1217-20.

63 Wade JPH, Mirsen TR, Hachinski VC, et al. The clinical diagnosis of Alzheimer's disease. Arch Neurol 1987;44: $24-9$. 